\title{
QUALITY IN HIGHER EDUCATION: THE MAINTENANCE PHASE OF THE INTERNAL QUALITY ASSURANCE SYSTEM ONE PORTUGUESE UNIVERSITY
}

\author{
N. Jesus-Silva ${ }^{1}$, A. Machado ${ }^{2}$ \\ 1 Universidade Portucalense, Infante D. Henrique (PORTUGAL) \\ 2 Universidade Portucalense, Infande D. Henrique (PORTUGAL) \\ natachajsilva@upt.pt, anam@upt.pt
}

\begin{abstract}
Theoretically, they are easy to enumerate the advantages of the existence of an IQAS (Internal Quality Assurance System) implemented in an accredited HEI. In practice, it is very difficult after obtaining certification / accreditation, maintaining it in order to feel the effects of quality management as a whole.

The maintenance phase is in fact the most difficult and complex of a IQAS. Implementation requires knowledge, discipline and the involvement of all subjects in the organization. After certification, the Quality Office is responsible for the difficult task of "policing" all teaching and nonteaching staff in order to ensure that they are adopting and complying with the procedures designed for each activity. It is also relevant to monitor and understand whether they are properly aware and involved in the spirit of continuous improvement of the organization. However, this task has as a basic principle a policy of raising awareness among all active subjects of the Educational Institution. Quality is not an obligation, but rather a facilitating lever for the Institution to be different in the market through a service provided with levels of excellence. If everyone is aligned on the notion of what quality management is, it is viewed lightly, enters the work that everyone does on a daily basis, and is normalized with fundamental effects on the final product provided.

The objective of this article is to inform the mainly academic community about the real and real difficulties of maintaining a SIGQ with standards with high levels over time, given the dispersion of active subjects in view of the daily need to deal with and comply with the procedures.

The IQAS must be set up in a chain in order to understand when there is a default by one of the subjects. Thus, the system itself must "accuse" the non-compliance by not allowing it to continue and achieve its intended purpose without quality standards.

A practical example will be given of the moment that is considered most difficult for the SIGQ, maintenance phase, which is where the systems end up falling, the accreditations are lost and fundamentally, there is no quality in Higher Education.
\end{abstract}

Keywords: Accreditation; Certification; Maintenance; Institution of Higher Education; Internal Quality Assurance System. 